Thermodynamic Characterization of Binary Mixtures of Smectic Phase Liquid Crystals

Juman A. Naser and Zainab W. Ahmed

\title{
Thermodynamic Characterization of Binary Mixtures of Smectic Phase Liquid Crystals
}

\author{
Juman A. Naser ${ }^{1}$ and Zainab W. Ahmed ${ }^{2}$ \\ ${ }^{1,2}$ Department of Chemistry- College of Education for Pure Science- Ibn Al-Haitham- University of \\ Baghdad
}

Received 13 April $2016 \quad$ Accepted 10 May 2016

\begin{abstract}
$\underline{\text { Abstract }}$
The binary mixture of 1-(para-Chloro benzylidene amino) -4-(2-n-hexylthio-1,3,4-oxadiazole5yl) benzene and 1-(para-Nitro benzylidene amino)-4-(2-n-hexylthio-1,3,4-oxadiazole-5yl) benzene with different mole fractions has been characterized by a hot stage polarizing optical microscope (POM) to determine the type of texture, then investigated by differential scanning calorrimetry (DSC) technique to determine the specific enthalpies and transition temperatures of phases. The enthalpies of mixing have been calculated to suggest the molecules type. Continuously, The thermodynamic excess quantities $\left(\mathrm{G}^{\mathrm{E}}, \mathrm{S}^{\mathrm{E}}\right.$ and $\left.\mathrm{H}^{\mathrm{E}}\right)$ were calculated by utilizing activity coefficient value of eutectic and isotropic phase, so molecular interactions behavior was described.
\end{abstract}

Keywords: Liquid crystals, Smectic, Binary system, Excess thermodynamic functions.

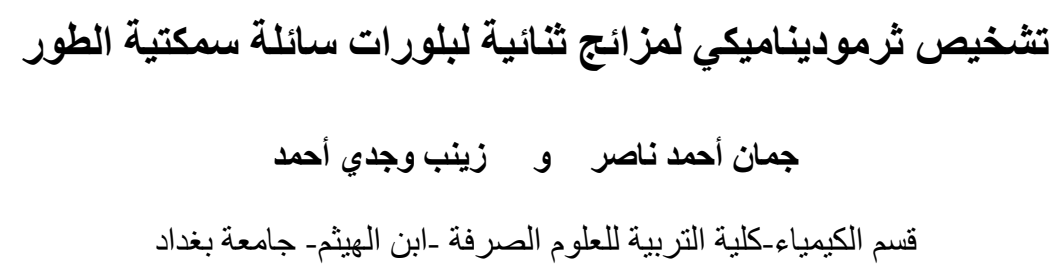




\section{Thermodynamic Characterization of Binary Mixtures of}

Smectic Phase Liquid Crystals

Juman A. Naser and Zainab W. Ahmed

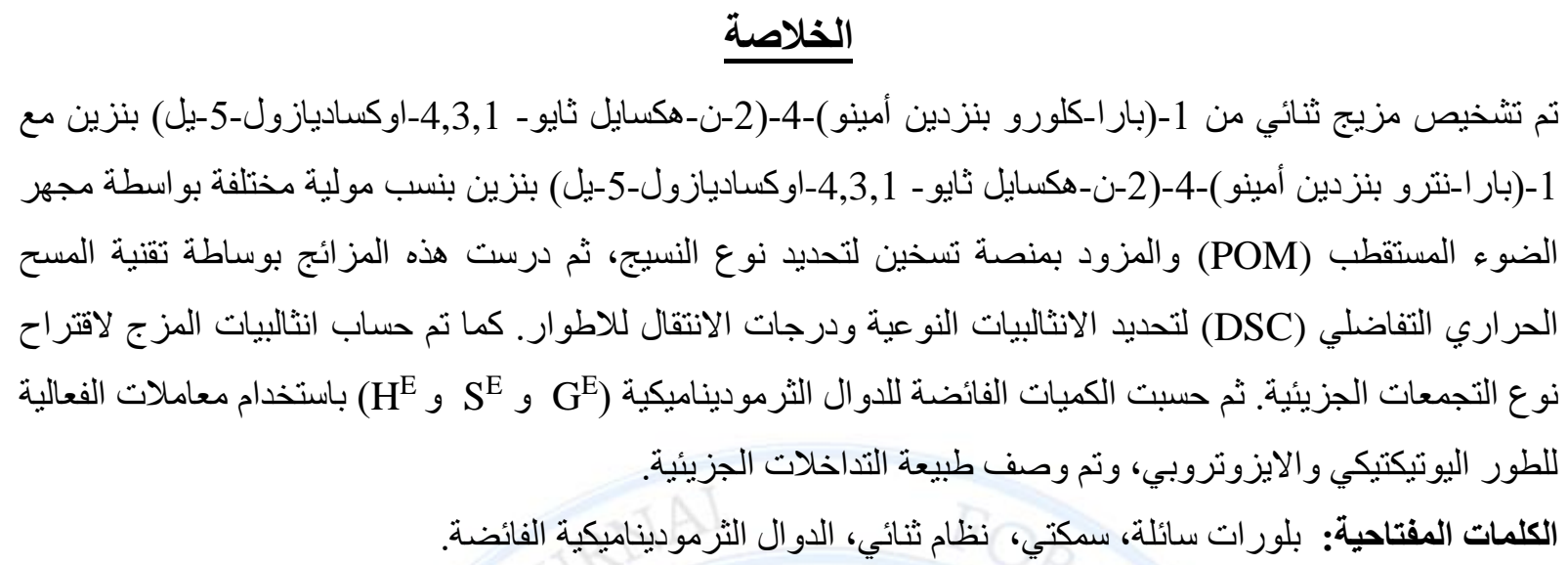

\section{Introduction}

The importance of liquid crystals lies in their a wide range of technological applications in display devices and other optical devises [1-4]. They are also attractive compounds for fundamental studies because of their structural, transitional, orientational, thermal and optical properties [5,6]. Liquid crystals are phases of matter whose intermediate between a crystalline solid and an isotropic liquid, that called mesophases [7-9]. A variety of mesophases attributed to differences in orientational and spatial ordering of molecules. Nematic $(\mathrm{N})$ and smectic $(\mathrm{Sm})$ phases are commonly intermediated phases between the crystal (C) and the isotropic liquid (I) [10].

Regarding importance and unique applications of liquid crystals, some requirements and characteristics need to be satisfied, such as the existence of the mesophase at the desired temperature of operation and the stability of mesophase range. Although there are many liquid crystalline materials, some difficulty is often experienced in achieving technologically useful temperature range for the existence of mesophase and response to external fields, as well as stability of the substance. To overcome this difficulty, mixture can be used . A binary mixture has transitions at temperatures in between the transition temperature of the pure compounds [11].

The thermodynamic data of solidus-liquidus equilibrium which obtained from differential scanning calorimetry (DSC) give many important thermodynamic functions in studies of binary mixtures [12]. Continually, in the thermodynamic considerations eutectic term can be 
Thermodynamic Characterization of Binary Mixtures of Smectic Phase Liquid Crystals

Juman A. Naser and Zainab W. Ahmed

defined as a heterogeneous system that containing on two or more solidus phase which are in an equilibrium with a single liquidus phase, so for this corresponds the lowest liquidus temperature in the binary solidus - liquidus diagram of state [13]. There are a few binary mixtures, which conform to simple eutectic behavior [14], whereas the others do not [15].

In many cases it is not always possible to bring down the temperature range of mesophase concerned without affecting the properties of the constituent pure components [16].

The present work is details studied concerning phase diagram, determination of excess thermodynamic quantities $\mathrm{G}^{\mathrm{E}}, \mathrm{S}^{\mathrm{E}}$ and $\mathrm{H}^{\mathrm{E}}$, the mixing behavior and the interactions of binary systems are discussed.

\section{$\underline{\text { Experimental }}$}

Materials: 1-(para-Chloro benzylidene amino)-4-(2-n-hexylthio-1,3,4-oxadiazole-5yl) benzene and 1-(para-Nitro benzylidene amino)-4-(2-n-hexylthio-1,3,4-oxadiazole-5yl) benzene were synthesized and characterized spectral by IR and ${ }^{1}$ HNMR technique then published in previous work [17].

Sample preparation: Six different mole ratios of binary mixtures were prepared by weighing out pure samples by using electro-balance of (Sartorius model BL210S) molar percents in different ratios of binary mixtures $\left[\mathrm{Cl}-\mathrm{SR}_{6}\right]$ and $\left[\mathrm{NO}_{2}-\mathrm{SR}_{6}\right]:(0.15 \mathrm{~A}),(0.30 \mathrm{~A}),(0.45 \mathrm{~A})$, $(0.60 \mathrm{~A}),(0.75 \mathrm{~A})$ and $(0.90 \mathrm{~A})$. Before taking the measurements, these mixtures have been dissolved in acetone, then mixed well and naturally evaporated.

Thermal analysis: Thermodynamic properties of these mixtures were realized by differential scanning calorimetry (Linseis STA PT-1000) instruments under a heating rate of $5^{\circ} \mathrm{C}$ per minute and nitrogen atmosphere in the range of temperatures $(5-180){ }^{\circ} \mathrm{C}$. Standard indium has been used for calibrating temperature and enthalpy. Sample of (11-6) mg were transferred into aluminum crucibles.

Mesomorphic properties: Different mesophases have been identified by using polarizing optical microscope (POM) (Olympus model BX40) equipped with a hot stage (Leitz Labrix12 pols) and controller (PR 660). The textures of binary mixtures have been observed by preparing a sandwich film of sample between a glass slide and cover slip of microscope. 


\section{Thermodynamic Characterization of Binary Mixtures of}

Smectic Phase Liquid Crystals

Juman A. Naser and Zainab W. Ahmed

\section{Results and Discussion}

The general structure of pure compounds showed in Scheme (1).

A:

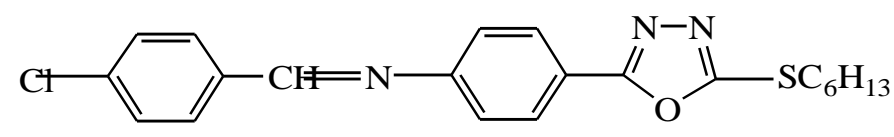

[Cl-SR

B:

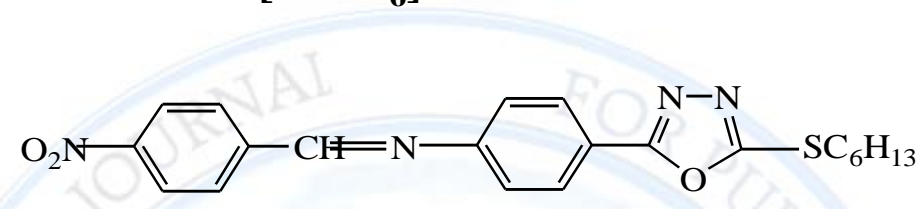

\section{$\left[\mathrm{O}_{2} \mathrm{~N}-\mathrm{SR}_{6}\right]$}

Scheme (1).

The thermal analyses of pure compounds $\left[\mathrm{Cl}-\mathrm{SR}_{6}\right]$ and $\left[\mathrm{NO}_{2}-\mathrm{SR}_{6}\right]$ which obtained from DSC are abstracted in Table (1).

The mesophase type textures of different mole ratios were characterized by a hot stage polarizing optical microscope (POM) throw heating cycle (crystal phase Cr-liquid crystal LC - isotropic phase I) and cooling cycle (isotropic phase I - liquid crystal LC - crystal phase $\mathrm{Cr}$ ). All these mixtures exhibited enatiotropic smectic Sm phases as shown in Figure (1). The transition temperatures and enthalpies of all mole fractions for binary mixture were determined by DSC measurements, Figures (2), (3), (4), (5), (6) and (7) show the thermal analysis of binary mixtures. The phase diagram of crystal-smectic and smectic-isotropic phase of the studied binary system is shown in Figure (8), the first peak refers to eutectic temperature while the second peak attribute to isotropic transition. The melting temperature of $\left[\mathrm{NO}_{2}-\mathrm{SR}_{6}\right]$ is $(414.95) \mathrm{K}$ and its decreases with addition of [Cl-SR 6 , so the mixture take the minimum eutectic point at (0.45) mole fraction.

The enthalpy of mixing for binary mixture is determined from the following equation (1) [10]:

$$
\Delta^{M} \mathrm{H}=\left(\Delta^{f} H\right)_{\exp .}-\sum\left(x_{i} \Delta^{f} H_{i}^{o}\right)
$$




\section{Thermodynamic Characterization of Binary Mixtures of}

\section{Smectic Phase Liquid Crystals}

Juman A. Naser and Zainab W. Ahmed

Where $\left(\Delta^{f} H\right)_{\text {exp. }}$ is the experimental value of enthalpy of fusion, $x_{i}$ is mole fraction and $\Delta^{f} H_{i}^{o}$ is enthalpy of fusion of the pure components.

Thermo chemistry suggests that, the type of structure of binary mixtures determines depending on the sign and value of enthalpy of mixing. Therefore, there are three kinds of structures that suggested: (a) quasi eutectic for mixture which has $\Delta^{M} \mathrm{H}>0$, (b) clustering of molecules in mixture which has $\Delta^{M} \mathrm{H}<0$, and (c) molecular solutions, for mixture which has $\Delta{ }^{M} \mathrm{H}=0$ [10]. In this studied system, the negative values of $\Delta^{M} \mathrm{H}$ refer to there is a clustering in molecules of the binary mixture melts, as shown in Table (2).

The deviation from an ideal behavior can be proposed through calculating excess thermodynamic functions which give more quantities insight concerning the specificities of the molecular interactions. The excess thermodynamic quantities are obtained by the difference between the thermodynamic functions of mixing for an experimental mixture and the analogous values for an ideal mixture at the same pressure and temperature conditions.

Additionally, to understanding the nature of interactions between components which forming eutectic mixture, the thermodynamic excess quantities; the excess free energy $G^{\mathrm{E}}$, the excess entropy $\mathrm{S}^{\mathrm{E}}$ and the excess enthalpy $\mathrm{H}^{\mathrm{E}}$ can be calculated.

The excess free energy $\mathrm{G}^{\mathrm{E}}$ was estimated by using the following equation[18,19]:

$$
G^{E}=R T\left[x_{1}^{l} \ln \gamma_{1}^{l}+x_{2}^{l} \ln \gamma_{2}^{l}\right]
$$

Where $x_{i}^{l}$ is the mole fraction, $\gamma_{1}^{l}$ is activity coefficient, $\mathrm{R}$ is the gas constant and $\mathrm{T}$ is the liquidus temperature.

The activity coefficient values of a component $i$ in attendance the mixture melt is estimated by:

$$
-\ln x_{i}^{l} \gamma_{i}^{l}=\frac{\Delta^{f} H_{i}^{o}}{R}\left[\frac{1}{T}-\frac{1}{T_{i}^{o}}\right] \ldots \ldots \ldots \ldots
$$

Where $\Delta^{f} H_{i}^{o}$ is heat of fusion. 


\section{Thermodynamic Characterization of Binary Mixtures of}

\section{Smectic Phase Liquid Crystals}

\section{Juman A. Naser and Zainab W. Ahmed}

The positive magnitudes of the excess free energy $G^{E}$, indicates that there is a weak interactions between the two binary components which forming the mixture melt then a strong association among the similar molecules [20]. Therefore, [Cl-SR 6$]-\left[\mathrm{NO}_{2}-\mathrm{SR}_{6}\right]$ attractive interaction forces are larger than that of $\left[\mathrm{Cl}-\mathrm{SR}_{6}\right]-\left[\mathrm{Cl}-\mathrm{SR}_{6}\right]$ association. Continuously, the magnitudes of excess enthalpy $H^{E}$ and entropy $S^{E}$ are very much correlated with $G^{E}$ values.

The excess entropy $S^{\mathrm{E}}$ values have been estimated by using the following equation $[18,20]$ :

$$
S^{E}=-R\left[x_{1}^{l} \ln \gamma_{1}^{l}+x_{2}^{l} \ln \gamma_{2}^{l}+x_{1}^{l} T\left(\frac{\partial \ln \gamma_{1}^{l}}{\partial T}\right)_{P}+x_{2}^{l} T\left(\frac{\partial \ln \gamma_{2}^{l}}{\partial T}\right)_{P}\right]
$$

Equation (3) is derived from corresponding the general conditions of phase equilibrium between the two phases, the enthalpy of fusion is independent of temperature, so the binary mixture is miscible at all ratios in the liquid phase only. Then, the values of $\left(\frac{\partial \ln \gamma_{1}^{l}}{\partial T}\right)_{P}$ can be estimated by using equation (5) which obtained from differentiating equation (3) [21]:

$$
\frac{\partial \ln \gamma_{1}^{l}}{\partial T}=\frac{\Delta^{f} H_{i}^{o}}{R T^{2}}-\frac{1}{x_{i}} \frac{\partial x_{i}}{\partial T}
$$

The values of excess functions for the crystal-smectic and smectic-isotropic phase transitions are shown in Table (2) and (3) respectively.

The functions of excess free energy $G^{E}$ and excess entropy $S^{E}$ for the crystal-smectic and smectic-isotropic phase transitions are drawn graphically in Figure (9) and (10) respectively. In view of the analysis of the Table (2) and graph (9), the excess free energy values of mixing $G^{E}$ increase and reaches maximal magnitude at the eutectic binary composition, that accruing at the lowest liquidus temperature acquired by the addition of the one component to another gradually. The nature of the behavior is dependable on the spontaneous of mixing according which appear at the eutectic phase. Thus the excess entropy of mixing $S^{E}$ have the minimal magnitude at the eutectic composition, since the perfect possible distribution of the molecules in the eutectic mixture occurs in the eutectic composition that required to the equilibrium of the three phases (two solidus phases and a liquidus phase). 


\section{Thermodynamic Characterization of Binary Mixtures of}

\section{Smectic Phase Liquid Crystals}

Juman A. Naser and Zainab W. Ahmed

The excess free energy $\mathrm{H}^{\mathrm{E}}$ was calculated using the following equation [19, 22]:

$$
H^{E}=-R T^{2}\left[x_{1}^{l}\left(\frac{\partial \ln \gamma_{1}^{l}}{\partial T}\right)_{P}+x_{2}^{l}\left(\frac{\partial \ln \gamma_{2}^{l}}{\partial T}\right)_{P}\right]
$$

The binary studied mixtures are endothermic in nature, since this system had positive deviations from its ideal behavior as a result to the positive values of excess free energy $G^{E}$ and negative values of excess entropy $S^{E}$.

\section{Conclusions}

All mole ratios of mixture exhibited enatiotropic smectic phase, there is no new phase as compare with pure liquid crystal compounds $\left[\mathrm{Cl}-\mathrm{SR}_{6}\right]$ and $\left[\mathrm{NO}_{2}-\mathrm{SR}_{6}\right]$.

The negative values for all mole ratios studied of the enthalpy of mixing, suggest that there is clustering in molecules of the binary system.

The positive magnitude of excess free energy value $G^{E}$, propose that there is a weak interactions between the two components $\left[\mathrm{Cl}-\mathrm{SR}_{6}\right]$ and $\left[\mathrm{NO}_{2}-\mathrm{SR}_{6}\right]$, which forming the binary melt then a strong association among the similar molecules $\left[\mathrm{Cl}-\mathrm{SR}_{6}\right]-\left[\mathrm{Cl}-\mathrm{SR}_{6}\right]$ and $\left[\mathrm{NO}_{2}-\right.$ $\left.\mathrm{SR}_{6}\right]-\left[\mathrm{NO}_{2}-\mathrm{SR}_{6}\right]$.

\section{References}

1. Dunmur D. A., "Liquid crystals", Fundamentals, World Scientific, New York, (2002).

2. Kato T., "Self -Assembly of phase -Segregated liquid crystal structures", Science, 495, 2414-2418, (2002).

3. Cosquer G. Y., "Liquid Crystals with novel terminal chains as ferroelectric hosts", Ph.D. Thesis, University of Hull, England, (2000).

4. Iannacchione G. S., "Review of liquid crystal phase transitions with quenched random disorder", Fluid Phase Equlib., 177-187, (2004).

5. McQueen D., Edgren K.A. and Rydman S., "Observation of high-speed nematic-tocrystal phase transition in p-azoxyphenetole", J. Phys. D: Appl. Phys. 7, 935-936, (1974).

6. Leheny R.L., Park S., Birgeneau R. J., Gallani J.L., Garland C.W. and Iannacchione G.S., "X-ray scattering I. Smectic ordering in liquid-crystal-aerosil dispersions", Phys. Rev., E 67, 011708-1170813, (2003).

7. Demus, D.; Goodby, J.; Gray, G. W.; Spiess, H. W. and Vill, V., "Handbook of Liquid Crystals", 1, Wiley-VCH, New York, (1998). 
Thermodynamic Characterization of Binary Mixtures of Smectic Phase Liquid Crystals

Juman A. Naser and Zainab W. Ahmed

8. Chong, T.T.; Heidelberg, T.; Hashim, R. and Gary, S., "Computer modelling and simulation of thermo tropic and lyotropic alkyl glycoside Bilayers", Liq.Cryst., 34, 267281, (2007).

9. Yoshizawa, A.; Nakata, M. and Yamaguchi, A., "Phase transition behaviour of novel Yshaped liquid crystal oligomers", Liq. Cryst., 33, 605-609, (2006).

10. Thoen J., Marynissen H., Van Dael W., "Temperature dependence of the enthalpy and the heat capacity of the liquid-crystal octylcyanobiphenyl (8CB)", Phys. Rev., A 26, 28862905, (1982).

11. Delica S., Estonactocy M., Micaller M. C., Cada L., and Domingo Z., "Phase diagram of binary Mixture E7:TM74A Liquid crystals", Science Diliman, 11, 2, 22-24, (1999).

12. Sharma B. L., Sharma N. K. and Bassi P. S., "Microstructures of binary organic eutectics", Journal of crystal growth, 67, 3, 633-638(1984).

13. Meltzer V., "Thermodynamic chemical", Editura University, Bucurest, , 7, 315-317 (2007).

14. Lisetski L. N., Batrachenko L. A., PaniKarskaya L., "Effects of Polar Interactions and Molecular Packing upon the Induced Smectic Mesomorphism", Mol. Cryst. Liq. Cryst, 215, 287-294, (1992).

15. Delica S., Estonactoc M., Micaller M. C., Cada L., and Domingo Z., "Molecular Crystals and Liquid Crystals Science and Technology. Section A. Molecular Crystals and Liquid Crystals", Mol. Cryst. Liq. Crys., 366, 101-106, (2001).

16. Srivastavas L., Dhar R. L. and Mukherjee A., "Thermodynamical Properties of Bicomponent Mixtures of Liquid Crystals Cholesteryl Pelargonate and Nonyloxybenzoic Acid", Mol. Cryst., 287, 139-154 (1996).

17. Naser J. A., "Mesomorphic and dielectric properties of heterocyclic liquid crystals with different terminal groups", Ibn Al-Haitham J. for Pure \& Appl. Sci., 29,1, 239-253, (2016).

18. Rai U. S. and Pandey P. ,"Solidification and thermal behaviour of binary organic eutectic and monotectic; succinonitrile-pyrene system", J. Cryst. Growth, 249, 301-8, (2003).

19. Sharma B. L., Kant R., Sharma R. and Tandon S., "Deviations of binary organic eutectic melt systems", Materials chemistry and Physics, 82, 216-24 (2003).

20. Meltzer V. and Pincu E., "Thermodynamic characterization of binary liquid crystal mixtures", Ann. Univ. Buc. 1, 15-18 (2008).21- Lerdkanchanaporn S., Dollimore D., Evans S. J., "Phase diagram for the mixtures of ibuprofen and stearic acid", Thermochim. Acta 367, 1-8 (2001).22- B.L. Sharma, R. Kant, S. Tandon, S. Gupta, "Physico-mechanical properties of naphthalene-acenaphthene eutectic system by different modes of solidification", Mater. Chem. Phys. 111, 423-430 (2008). 


\section{DIVALA JOURNAL FOR PURE SCIENCES}

Thermodynamic Characterization of Binary Mixtures of

Smectic Phase Liquid Crystals

Juman A. Naser and Zainab W. Ahmed

Table (1): Transition temperatures and enthalpies for pure compounds.

\begin{tabular}{|c|c|c|c|c|c|}
\hline Compounds & Molecular weight $(\mathbf{g} / \mathbf{m o l})$ & $\mathbf{T}_{\mathbf{f}}(\mathbf{K})$ & $\Delta^{f} \boldsymbol{H}(\mathbf{J} / \mathbf{m o l})$ & $\mathbf{T}_{\mathbf{I}}(\mathbf{K})$ & $\Delta^{\boldsymbol{I}} \boldsymbol{H}(\mathbf{J} / \mathbf{m o l})$ \\
\hline$\left[\mathrm{Cl}_{-}-\mathrm{SR}_{6}\right]$ & 399.5 & 378.75 & +25635.9 & 408.95 & +4869.91 \\
\hline$\left[\mathrm{NO}_{2}-\mathrm{SR}_{6}\right]$ & 410 & 414.95 & +446.9 & 430.05 & +29647.1 \\
\hline
\end{tabular}

$* \Delta^{f} H$ and $\Delta^{I} H$ are enthalpy of fusion and isotrope of pure components respectively.

Table (2): Excess thermodynamic functions of binary system of [Cl-SR6] and [NO $\left.2-\mathrm{NR}_{6}\right]$

for crystal-smectic phase transition.

\begin{tabular}{|c|c|c|c|c|c|c|c|c|}
\hline$X$ & $X_{A}$ & $X_{B}$ & $\begin{array}{c}\Delta^{M} H \\
(\mathrm{~kJ} / \mathrm{mol})\end{array}$ & $\gamma_{A}$ & $\gamma_{B}$ & $\begin{array}{c}\mathrm{G}^{\mathrm{E}} \\
(\mathrm{kJ} / \mathrm{mol})\end{array}$ & $\begin{array}{c}\mathrm{S}^{\mathrm{E}} \\
(\mathrm{J} / \mathrm{mol} . \mathrm{K})\end{array}$ & $\begin{array}{c}\mathrm{H}^{\mathrm{E}} \\
(\mathrm{kJ} / \mathrm{mol})\end{array}$ \\
\hline 0.15 & 0.15 & 0.85 & -1.997 & 10.913 & 0.915 & 1.005 & 21.640 & -29.041 \\
\hline 0.30 & 0.30 & 0.70 & -1.817 & 4.018 & 0.893 & 1.220 & -74.410 & -28.434 \\
\hline 0.45 & 0.45 & 0.55 & -2.610 & 2.876 & 1.077 & 1.679 & -75.398 & -27.828 \\
\hline 0.60 & 0.60 & 0.40 & -0.957 & 1.736 & 1.159 & 1.226 & -75.464 & -27.221 \\
\hline 0.75 & 0.75 & 0.25 & -1.086 & 1.374 & 1.820 & 1.225 & -74.761 & -26.615 \\
\hline 0.90 & 0.90 & 0.1 & -1.167 & 1.064 & 4.181 & 0.623 & -73.264 & -26.008 \\
\hline
\end{tabular}

Table (3): Excess thermodynamic functions of binary system of [Cl-SR6] and [NO $\left.2-\mathrm{NR}_{6}\right]$ for smectic-isotropic phase transition.

\begin{tabular}{|c|c|c|c|c|c|c|c|c|}
\hline$X$ & $X_{A}$ & $X_{B}$ & $\begin{array}{c}\Delta^{M} H \\
(\mathrm{~kJ} / \mathrm{mol})\end{array}$ & $\gamma_{A}$ & $\gamma_{B}$ & $\begin{array}{c}\mathrm{G}^{\mathrm{E}} \\
(\mathrm{kJ} / \mathrm{mol})\end{array}$ & $\begin{array}{c}\mathrm{S}^{\mathrm{E}} \\
(\mathrm{J} / \mathrm{mol} . \mathrm{K})\end{array}$ & $\begin{array}{c}\mathrm{H}^{\mathrm{E}} \\
(\mathrm{kJ} / \mathrm{mol})\end{array}$ \\
\hline 0.15 & 0.15 & 0.85 & -13.535 & 6.958 & 1.140 & 1.4339 & -2.9727 & -0.850 \\
\hline 0.30 & 0.30 & 0.70 & -11.441 & 3.421 & 1.193 & 1.7254 & -8.8507 & -1.254 \\
\hline 0.45 & 0.45 & 0.55 & -11.863 & 2.293 & 1.612 & 2.2451 & -10.705 & -1.658 \\
\hline 0.60 & 0.60 & 0.40 & -12.194 & 1.729 & 2.311 & 2.3515 & -11.778 & -2.064 \\
\hline 0.75 & 0.75 & 0.25 & -15.411 & 1.379 & 3.621 & 1.9902 & -11.898 & -2.466 \\
\hline 0.90 & 0.90 & 0.1 & -10.144 & 1.137 & 8.207 & 1.1426 & -11.000 & -2.870 \\
\hline
\end{tabular}




\section{DIYALA JOURNAL FOR PURE SCIENCES}

Thermodynamic Characterization of Binary Mixtures of

Smectic Phase Liquid Crystals

Juman A. Naser and Zainab W. Ahmed

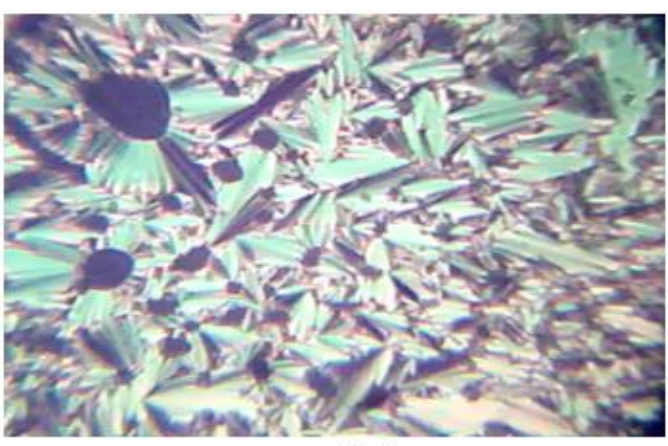

(a)

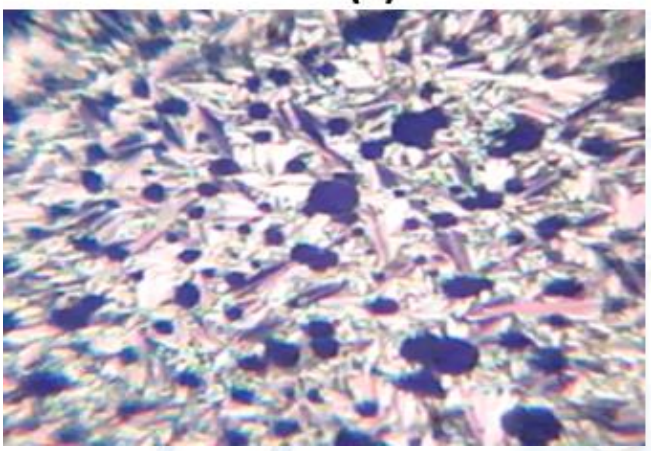

(c)

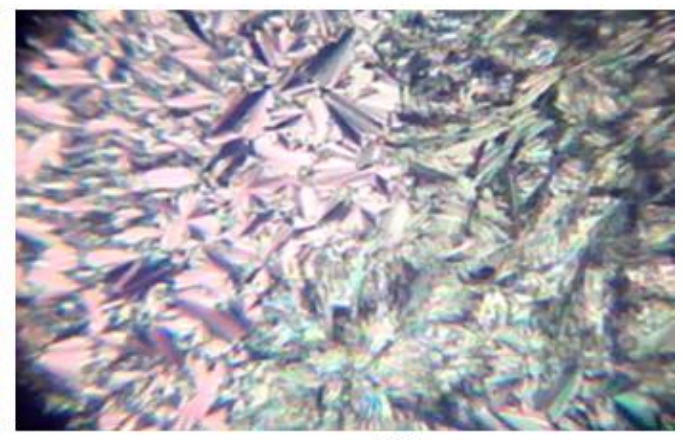

(b)

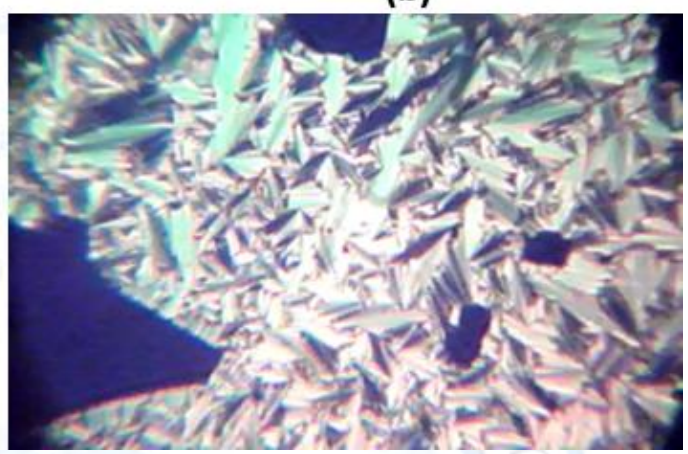

(d)

Figure (1): Polarizing photomicrograph on cooling: (a) A batonnets

$\mathrm{Sm}_{\mathrm{A}}$ texture at $132{ }^{\circ} \mathrm{C}$ for mole fraction $\mathrm{0.3A}$; (b) A batonnets $\mathrm{Sm}_{\mathrm{A}}$ texture at $115{ }^{\circ} \mathrm{C}$ for mole fraction $0.6 \mathrm{~A}$; (c) A focal conic $\mathrm{Sm}_{\mathrm{A}}$ texture at $120^{\circ} \mathrm{C}$ for mole fraction $0.75 \mathrm{~A}$ (d) A batonnets $\mathrm{Sm}_{\mathrm{A}}$ texture at 138

${ }^{\circ} \mathrm{C}$ for mole fraction $0.9 \mathrm{~A}$.

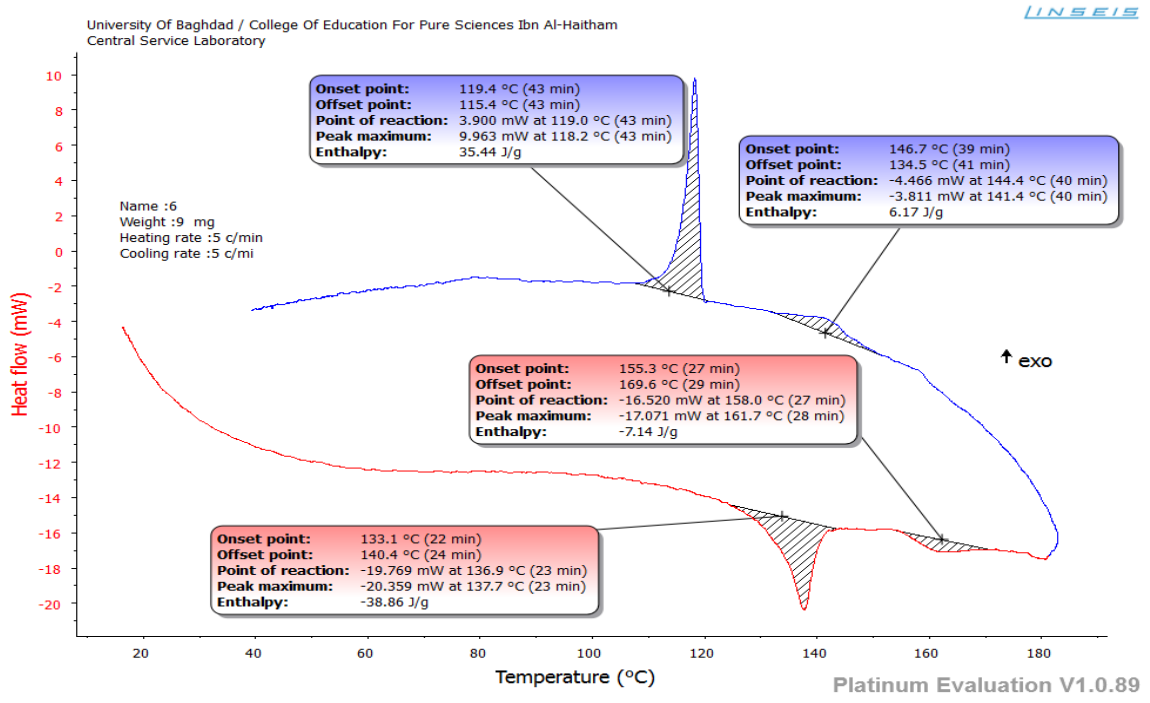

Figure (2): DSC- Thermogram for heating and cooling of mole fraction 0.15A [Cl-SR6]. 


\section{DIYALA JOURNAL FOR PURE SCIENCES}

Thermodynamic Characterization of Binary Mixtures of Smectic Phase Liquid Crystals

Juman A. Naser and Zainab W. Ahmed

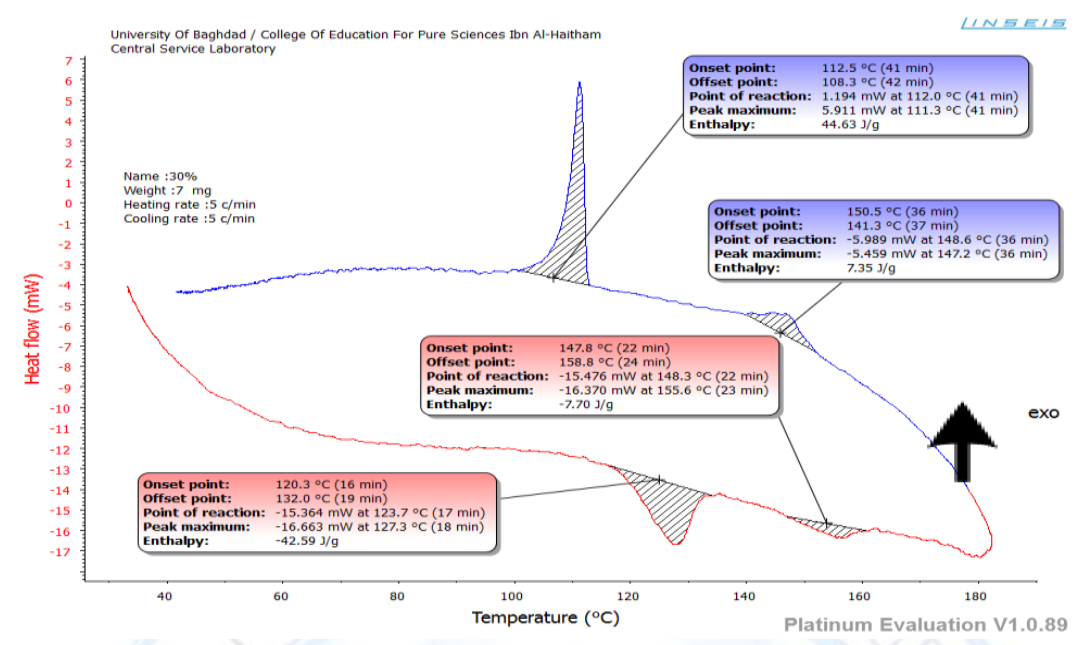

Figure (3): DSC- Thermogram for heating and cooling of mole fraction 0.3A [CI-SR6].

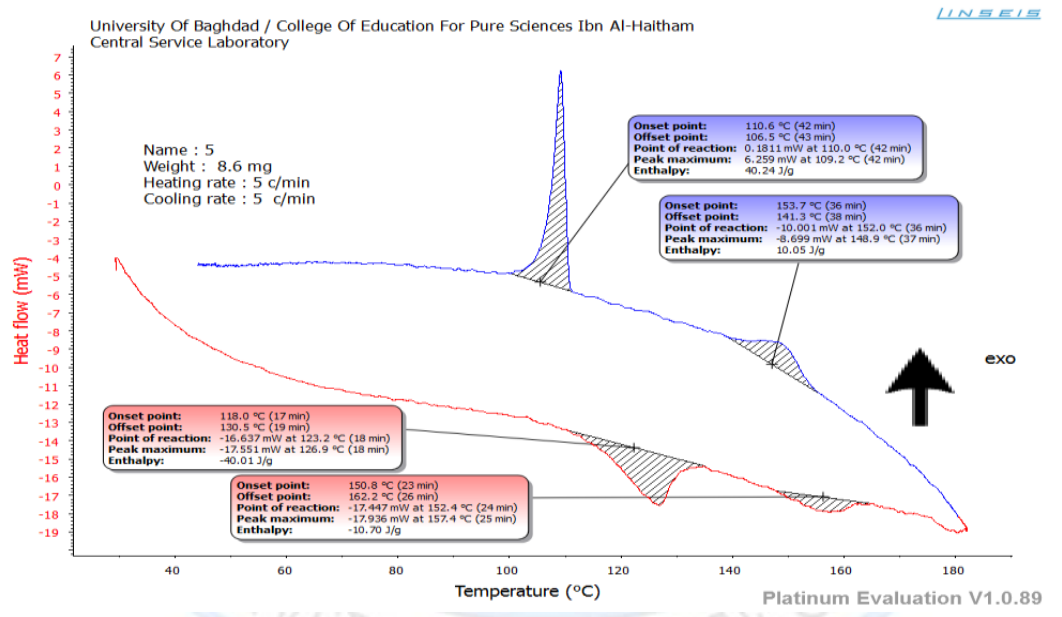

Figure (4): DSC- Thermogram for heating and cooling of mole fraction $0.45 \mathrm{~A}$ [Cl-SR6]. 


\section{DIYALA JOURNAL FOR PURE SCIENCES}

Thermodynamic Characterization of Binary Mixtures of Smectic Phase Liquid Crystals

Juman A. Naser and Zainab W. Ahmed

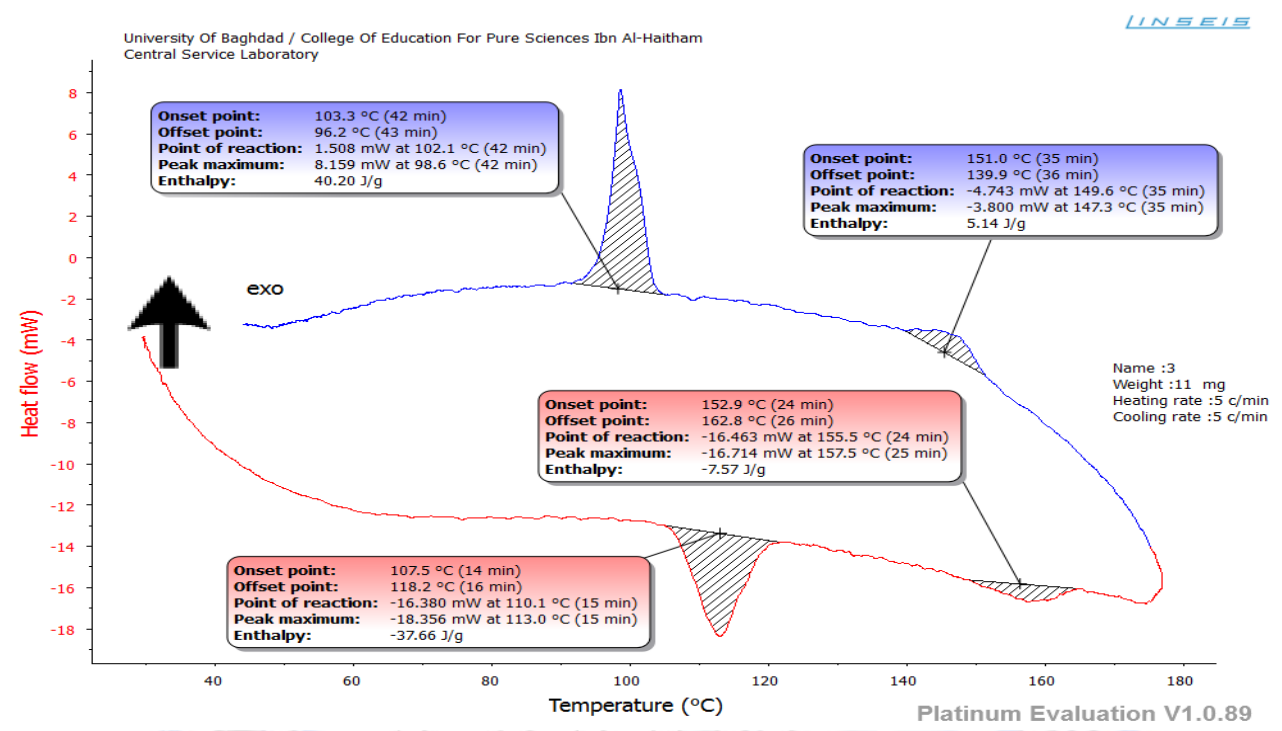

Figure (5): DSC- Thermogram for heating and cooling of mole fraction 0.6A [Cl-SR6] upon heating and cooling.

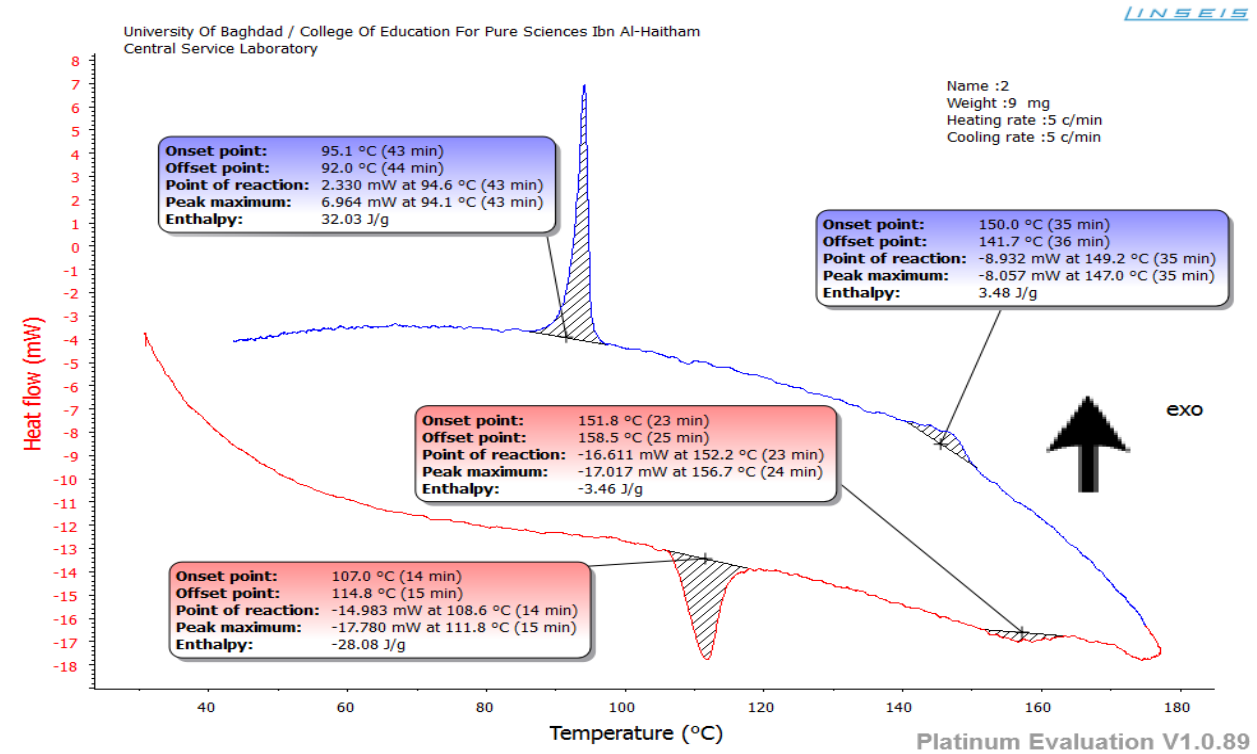

Figure (6): DSC- Thermogram for heating and cooling of mole fraction 0.75A [Cl-SR6]. 


\section{DIYALA JOURNAL FOR PURE SCIENCES}

Thermodynamic Characterization of Binary Mixtures of Smectic Phase Liquid Crystals

Juman A. Naser and Zainab W. Ahmed

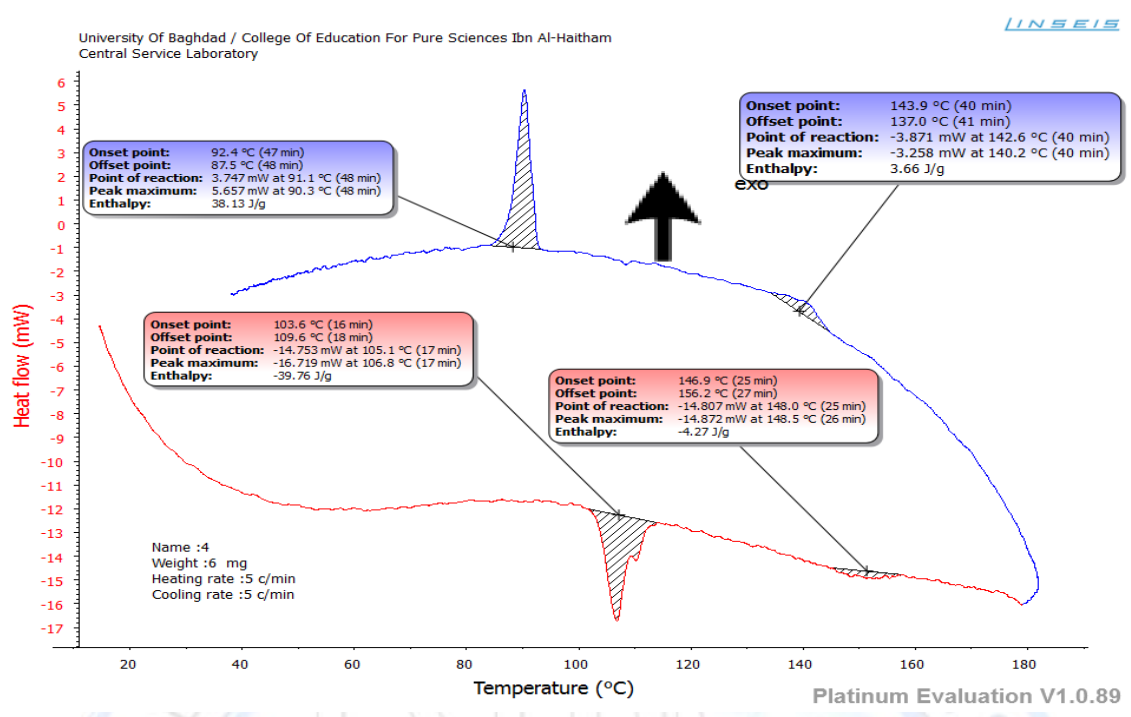

Figure (7): DSC- Thermogram for heating and cooling of mole fraction 0.9A [Cl-SR 6 .

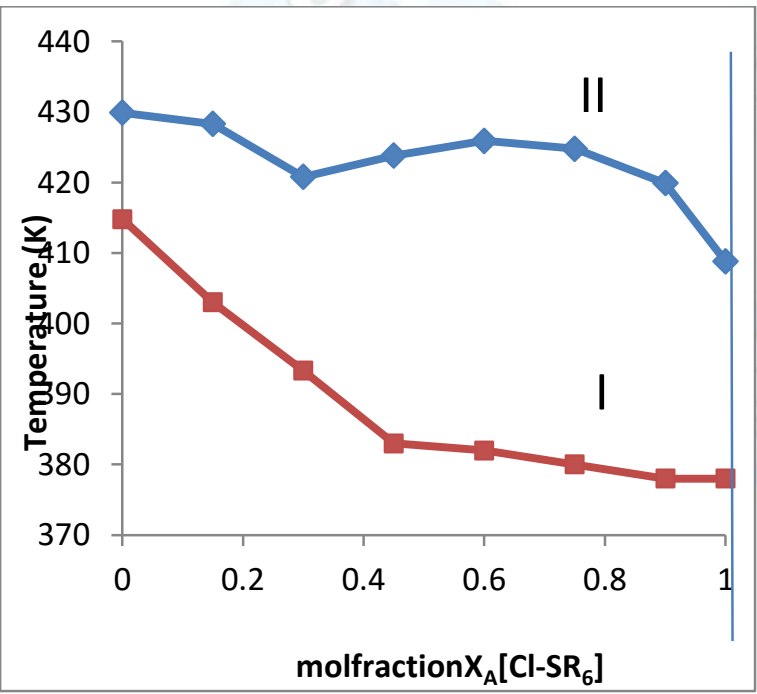

Figure (8): Phase diagram of binary mixture (I:liquid crystal phase, II: isotropic phase). 


\section{DIYALA JOURNAL FOR PURE SCIENCES}

Thermodynamic Characterization of Binary Mixtures of Smectic Phase Liquid Crystals

Juman A. Naser and Zainab W. Ahmed

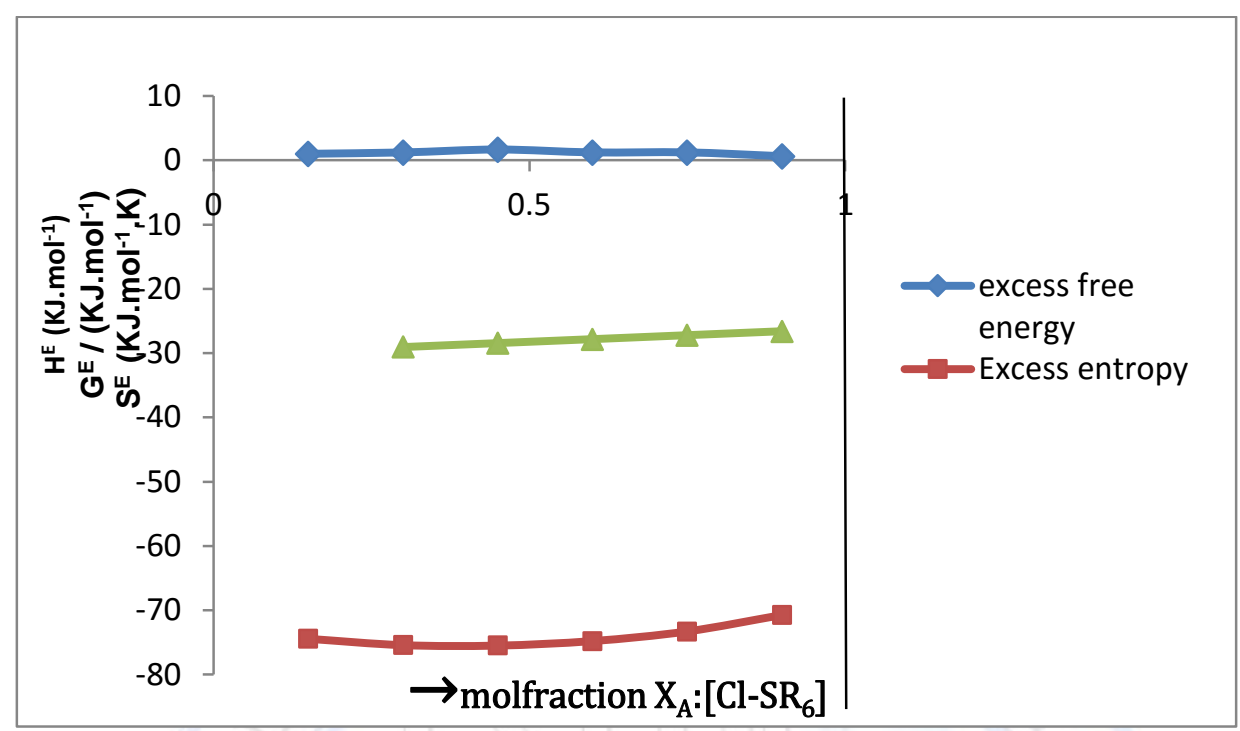

Figure (9): Excess thermodynamic functions of binary system of [Cl-SR6] and [NO2-SR6] for crystal-smectic phase transition.

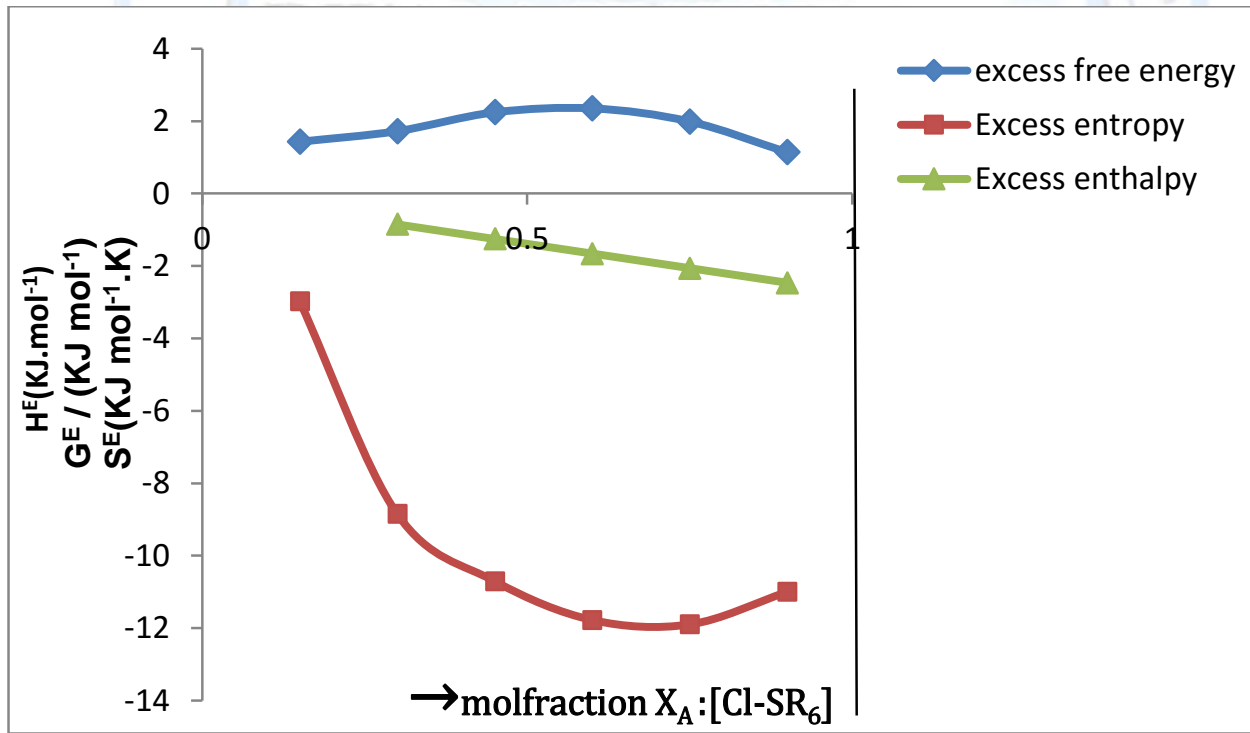

Figure (10): Excess thermodynamic functions of binary system of [Cl-SR6] and [NO2SR6] for smectic-isotropic phase transition. 